\title{
O Fragmento 2 W de Tirteu e a Poética da Eunomia
}

\author{
RAFAEL DE C.M.BRUNHARA \\ Universidade de São Paulo \\ Brasil
}

Resumo. Acreditou-se por muito tempo que a Eunomia de Tirteu (Fr.1 - 4 W) fosse um poema narrativo destinado à comunidade e entoado apenas no espaço do festival público. Atualmente a discussão permanece em aberto, sobretudo por causa da escassez dos fragmentos que restaram. Em vez de tentar neste trabalho conjeturar uma ocasião de performance específica para o poema, este texto visa responder as seguintes perguntas a partir da leitura do fragmento $2 \mathrm{~W}$ : Há marcas textuais que distinguem uma poética circunscrita aos eventos públicos e outra, própria do ambiente simpótico? Se sim, Pode-se dizer que a Eunomia de Tirteu apresenta tais marcas? PALAVRAS-ChaVE. Tirteu; poesia grega arcaica; performance; elegia narrativa.

Neste artigo pretende-se examinar os testemunhos de que teriam composto o poema de Tirteu intitulado Eunomia (Fr. $1-4 \mathrm{~W}$ ) e propor uma leitura ao Fragmento $2 \mathrm{~W}$ deste poema. O cerne da questão está no debate da ocasião de performance para a qual os versos da Eunomia teriam sido compostos. Seguindo a hipótese influente de Bowie ${ }^{1}$ hoje é possível alocar o corpus elegíaco em duas circunstâncias distintas com base na extensão de cada poema: uma pública, com longas elegias narrativas direcionadas a festivais cívicos e religiosos, e outra particular, voltada para as heterias aristocráticas do simpósio.

Acreditou-se por muito tempo que a Eunomia de Tirteu fosse um poema narrativo destinado à comunidade e entoado apenas no espaço do festival público. Sua temática civil favorece essa hipótese - o poema trataria possivelmente da colonização da região do Peloponeso (Fr. 2 W), da revolta que acometeu Esparta com o término da Segunda Guerra da Messênia e talvez um relato do primeiro conflito contra os Messênios (Fr. 5-7 W). Rösler $^{2}$ (1990, p. 233-234) revisitou a evidência e verificou pontos de

Email: rafael.brunhara@gmail.com

${ }^{1}$ E.L. Bowie. Early Greek Elegy, Symposium and Public Festival, JHS 106, 13-35, 1986.

${ }^{2}$ W. RösLer, 'Mnemosyne in the Symposium' in O.MurRay (ed.) Sympotica, a symposium on the symposium. Oxford, University Press, 1990. p.220-229. 
contato entre estes poemas e o ambiente do simpósio, sendo seguido por uma revisão de Bowie sobre a sua hipótese ${ }^{3}$ no que concerne à Eunomia.

Atualmente a discussão permanece em aberto, sobretudo por causa da escassez dos fragmentos que restaram. Stehle ${ }^{4}$ considera-a um exemplar de poesia da comunidade, enquanto D'Alessio ${ }^{5}$ chama-a de "elegia coral" e identifica, não só neste poema, mas em todo o corpus tirtaico, uma ideologia comunal adequada às syssitia, reuniões espartanas afins aos simpósios de outras poleis.

Em vez de tentar neste trabalho conjeturar uma ocasião de performance específica para o poema, este texto visa responder as seguintes perguntas a partir da leitura do fragmento $2 \mathrm{~W}$ : Há marcas textuais que distinguem uma poética circunscrita aos eventos públicos e outra, própria do ambiente simpótico? Se sim, haveria pontos de contato entre elas? Pode-se dizer que a Eunomia de Tirteu apresenta tais marcas?

\section{A Eunomia e a miragem espartana}

A Eunomia ocupa um lugar peculiar no corpus de elegias de Tirteu e talvez sem paralelo em outros poemas elegíacos gregos arcaicos, porquanto seus versos parecem aludir ao mais importante documento da história de Esparta, a assim chamada Grande Retra. De acordo com Plutarco, o documento foi outorgado pelo legislador semilendário Licurgo, que o trouxe de Delfos na forma de profecia (Plut.,Lyc. 6).

Acredita-se que a citação de Plutarco não seja uma transcrição exata do oráculo recebido por Licurgo, e sim o próprio texto da lei, que teria sido

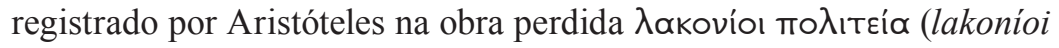
politeía $)^{6}$. O texto contém informações religiosas e administrativas, que demarcam o papel do povo ( $\delta$ á $\mu \omega)$ no processo de decisão política - a ele, relata Plutarco, apenas cabia aprovar ou reprovar as propostas oferecidas pelo conselho:

${ }^{3}$ E.L.Bowie, 'Ancestors of Herodotus in Early Greek Elegiac and Iambic Poetry' in N.LuRAghi (ed.) The Historian Craft in the age of Herodotus. Oxford, University Press, 2001. p. $45-47$

${ }^{4}$ E.Stehle, Performance and Gender in Ancient Greece. Princeton/New Jersey, 1997, p.51

${ }^{5}$ G.B. D'Alessio, 'Defining Local Identities in Greek Lyric Poetry' in I.Rutherford; R.Hunter (eds.) Wandering Poets in Ancient Greek Culture: Travel, Locality and PanHellenism. Cambridge/New York, Cambridge University Press, 2009, p.151.

${ }^{6}$ H. Wade-Gery, The Spartan Rhetra in Plutarch's Lycurgus VI. B - The Eunomia of Tyrtaios, CQ 38.1, p.115 1944.

${ }^{7}$ K. RaAflaub, 'Athenian and Spartan Eunomia or: what to do with Solon's timocracy?' in BLoK, J.H; Lardinols, A.P.M.H. Solon of Athens, new historical and philological ap- 


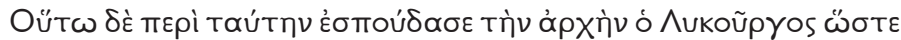

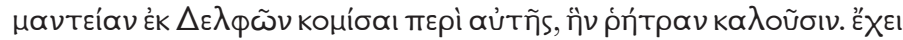

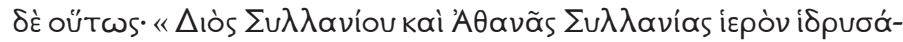

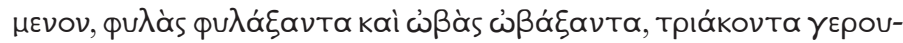

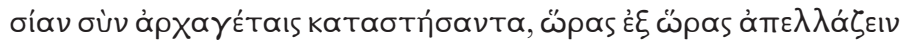

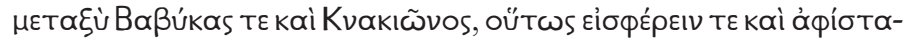

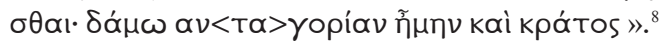

Licurgo zelou tanto pelo poder que trouxe de Delfos uma profecia sobre isso, a qual denominam Retra. Diz o seguinte: "Depois de fundar um templo de Zeus Silânio e Atena Silânia ${ }^{9}$, as tribos distribuir ${ }^{10}$, as obes $^{11}$ organizar e instalar um conselho de trinta anciões com os seus príncipes, realizar a apela ${ }^{12}$ de tempos em tempos entre Bábica e Cinácion. Dessarte, propõe e depõe, mas o poder e a respon $<\mathrm{sa}>$ bilidade será do povo." (Plut. Lyc. 6, 1-3)

No poema, Tirteu justificaria a autoridade do poder real e a validade das leis, afirmando que ambas estavam assentadas em estatutos divinos: os reis são descendentes de Héracles; a região do Peloponeso, uma dádiva de Zeus para eles; e a constituição, prescrita por Apolo.

proaches. Leiden/Boston: Brill, 2006, p. 395.

${ }^{8}$ As traduções são de minha responsabilidade, exceto quando especificado o contrário. A tradução deste excerto da Vida de Licurgo almeja ser apenas uma notícia, literal, do que diz o texto grego. Não é objetivo deste trabalho se deter na complexa (e ainda em aberto) discussão sobre as implicações e ambigüidades de cada termo político empregado. Ver D. OGDEN, Crooked speech: the genesis of the Spartan Rhetra, JHS 114, p.85-102, 1994, e sua tradução (1994,p.86): "[I order you], having founded a temple of Zeus Syllanios and Athene Syllania, having tribed/preserved the tribes and obed the obes, having estabilished 30 as a council of elders together with leaders/kings, from time to time to celebrate Apollo/hold assemblies between Babyca and Cnacion, thus to bring in and to set aside. Ultimate authority and power is to be the people".

${ }^{9}$ Ogden (1994,p.102) propõe para este epíteto a etimologia $\sigma u v-\lambda \alpha v-$ os, sendo $\sigma u v$

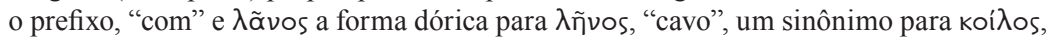
que em Homero é um epíteto para a região da Lacedemônia (Il.2. 581). - Ios é o sufixo formador de adjetivo. Assim, segundo o autor, Zeus e Atena recebem este epíteto porque seriam os protetores do vale entre Bábica e Cinácion.

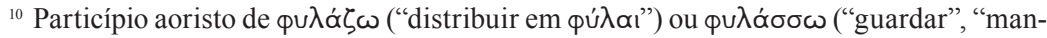
ter", "vigiar")? A primeira opção parece mais apropriada, tendo em vista um possível

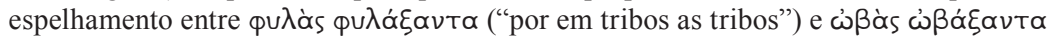
("por em obes as obes").

${ }^{11}$ As obes eram subdivisões das $\phi u ́ \lambda \propto \iota$ espartanas. (LSJ)

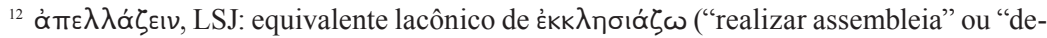
bater em assembleia"). A apela, dessarte, é o nome dado à assembleia popular espartana. 
Segundo Jäger ${ }^{13}$, Tirteu defendia uma constituição na qual o povo ocupava posição secundária, e os reis e anciões detinham grande poder de decisão. O contexto encontrado pelo erudito é de que, com o término da Segunda guerra da Messênia, o povo toma conta de sua força e passa a reivindicar maiores privilégios políticos de seus líderes; Tirteu, assumindo o papel de mentor e educador do estado, compõe a Eunomia com o intuito de relembrar o caráter sagrado da constituição e da origem espartana, e assim evitar um conflito.

Tal entendimento dos fragmentos de Tirteu incorre em um problema que os historiadores têm chamado de "Miragem Espartana"14. Quanto daquilo que sabemos da história espartana não é fruto de uma visão equivocada de autores estrangeiros, provocada pela distância, preconceito ou fascínio? Quanto não é parte de uma reinvenção tardia da tradição, operada no período Clássico e Helenístico ${ }^{15}$ ?

Nesse contexto de testemunhos escassos ou pouco confiáveis da história espartana, o poema de Tirteu ocupa um lugar maior do que poderia ter tido originalmente, cercando-se desde a Antiguidade de narrativas que o colocam como um registro importante da figura de Licurgo, das leis atribuídas a ele e da fundação da Esparta Clássica.

Mas quanto do poema de Tirteu refere-se explicitamente a um período particular da história espartana, e quanto não se trata da utilização de lugares-comuns da tradição poética grega arcaica?

Aristóteles (Pol., 5.1306b7) é o primeiro sugerir que a Eunomia fazia referências a um período de dissonância política que atingira Esparta no século VII a.C. Aristóteles apresenta a Esparta de Tirteu como exemplo para sua teoria de que conflitos no interior da polis estão atrelados à disparidade de riquezas entre os cidadãos. Embora não fale nada sobre os pedidos do povo por maiores direitos políticos, Aristóteles menciona que Esparta encontrava-se à beira de uma guerra civil por posse de terras:

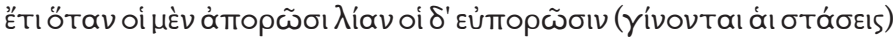

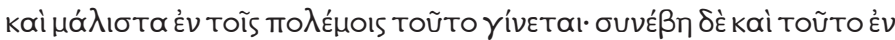

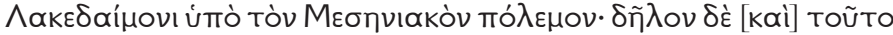

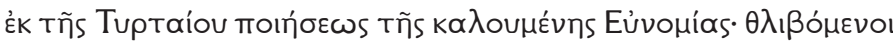

${ }_{13}$ apud A.L.Coimbra; V. De Falco, Os Elegíacos Gregos, de Calino a Crates, São Paulo, 1941. p. 158)

${ }^{14}$ Termo que ficou convencionado depois da publicação da obra de François Ollier, La Mirage Spartiate em 1933.

${ }^{15}$ M. Nafissi, 'Sparta' in K. Raaflaub; H. Van Wees (eds.) A Companion to Archaic Greece. 2009, West Sussex: Blackwell, 2009. p. 128 


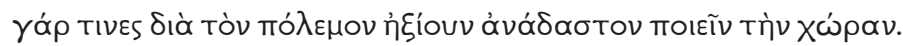

Ainda quando alguns estão demasiadamente sem recursos e outros prosperam (acontecem as sedições). Isso acontece, sobretudo, nas guerras: ocorreu também na Lacedemônia, durante a guerra messênica. Isso[ também] faz-se manifesto pelo poema de Tirteu, denominado Eunomia. Pois alguns, oprimidos por causa da guerra, achavam digno fazer uma redistribuição de terras.

A Descrição da Grécia de Pausânias informa com maiores detalhes do que Aristóteles o teor dos confrontos em Esparta. Durante a Guerra da Messênia, os espartanos teriam deixado inúmeras porções de terra sem cultivo, para que os messênios que habitavam a região do Ira não pudessem usufruir de seus campos. Com o fim da guerra, a escassez de alimentos levou à revolta da população e a ameaça de uma sedição interna (Paus. 4.18):

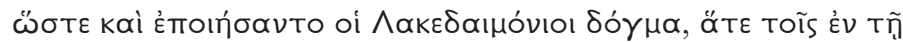

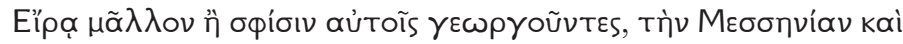

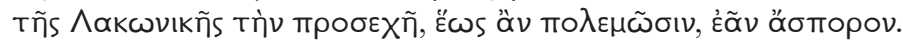

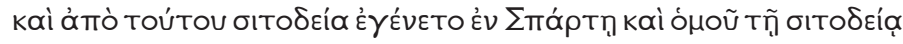

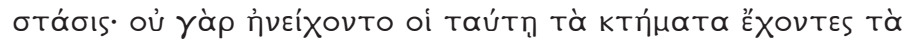

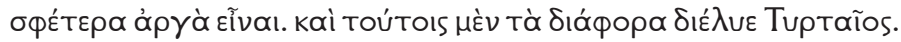

E desse modo os Lacedemônios, porque cultivavam a terra mais para os habitantes de Ira do que para eles próprios, tomaram a decisão de deixar Messênia e vizinhanças da Lacônia sem semeadura, enquanto guerreassem. Por isso houve carestia em Esparta, e juntamente com a carestia, a sedição: Pois os que tinham propriedades ali não suportavam que suas terras não fossem cultivadas. Tirteu resolveu a desavença entre eles.

Se o historiador Hans Van Wees ${ }^{16}$ está certo em suas hipóteses, o relato de Pausânias é uma invenção tardia, que tenta conciliar o mito de Licurgo - cujas leis transformaram Esparta em uma sociedade de iguais, bem antes do tempo de Tirteu ${ }^{17}$ - com a evidência fornecida por Aristóteles de uma desigualdade predominante na sociedade espartana. As con-

${ }^{16}$ H.VAn WeEs. 'Tyrtaeus Eunomia: Nothing to do with the Great Rhetra' in HodkInson,S. \& Powell, A. (org.) Sparta: new pespectives. Swansea, The Classical Press of Whales, 1999, p.2 ${ }^{17}$ Tirteu teria vivido duas gerações depois da diarquia dos reis Polidoro e Teopompo (Ver Fr.5.1.W) - que possivelmente combateram na Primeira Guerra da Messênia em tempos da $50^{\circ}$ Olimpíada, no último quartel do século VIII a.C.. Segundo Aristóteles, o oráculo recebido por Licurgo data de 776 a.C., época da $1^{\circ}$ Olimpíada. 
siderações de Pausânias refletem uma situação particular e sem paralelo na História de guerra da Grécia Antiga, podendo ser resultado de uma especulação posterior que visou adequar tanto a lenda de Licurgo como o poema de Tirteu na história espartana.

Para Van Wees ${ }^{18}$ é mais provável que Tirteu não tivesse referido explicitamente os eventos posteriores à guerra, mas somente feito uma ou outra alusão à necessidade de redistribuição de terras, do mesmo modo que Sólon em seus fragmentos. O Fragmento $34 \mathrm{~W}$ de Sólon, por exemplo, trata de um evento similar. Embora seja patente nos versos abaixo o desejo do Eu poético em direcionar a recepção de sua figura no poema ${ }^{19} \mathrm{o}$ poeta também alude nesse fragmento à necessidade de reformas (vv. 8-9) sem tecer narrativas de alguma crise política específica:

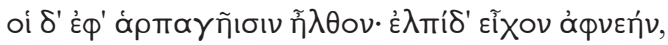

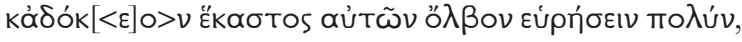

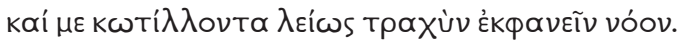

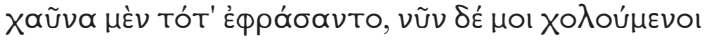

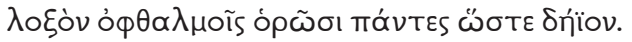

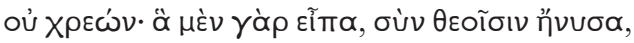

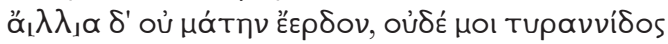

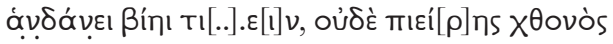

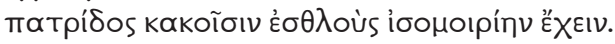

... Outros, vieram pela rapinagem, tinham esperança de riqueza e acreditavam, cada um deles, que encontrariam muita fortuna e que eu, lisonjeando com brandura, revelaria um espírito rude. aquela vez, ponderavam coisas frívolas; agora, irritados comigo, de soslaio olham-me todos, como a um inimigo, sem necessidade: Pois as coisas que eu disse, com Deuses cumpri; as demais, não realizei em vão, e com a violência da tirania não me apraz (?)... [. .], [i]r, nem que do pingue solo pátrio os nobres tenham igual quinhão que os vis.

Ademais, este procedimento antes alusivo do que descritivo pode constituir um traço do gênero: como trata de um momento contemporâneo à sua performance ${ }^{20}$, poderia parecer redundante ao poeta descrever os pormenores da situação política.

${ }^{18}$ H. VAN WeEs, 1999, p. 2

${ }^{19}$ E. Irwin, Solon and Early Greek Poetry, The Politics of Exhortation. Cambridge, University Press, 2005, p.133

${ }^{20} \mathrm{Ou}$, supostamente, não tão recuado como de grandes epopeias como a Ilíada e a Odisseia. (Ver West 1974). 
Da leitura das fontes pode-se aduzir apenas que Tirteu certamente teria mencionado em seus poemas a ameaça da otóoııs que pairava então na sociedade espartana, filiando-se assim a um tema tradicional da poesia elegíaca grega arcaica. ${ }^{21}$

Um adágio espartano outrora atribuído a Tirteu ${ }^{22}$, se considerado legitimamente arcaico, coloca Esparta no mesmo patamar de outras poleis arcaicas virtualmente contemporâneas (como a Atenas de Sólon ou Mégara dos poemas teognídeos) e introduz uma tópica comum a esta tradição poética: a ganância e a desmedida do povo são responsáveis por levar uma cidade à ruína. O provérbio encontra-se na Biblioteca Histórica de Diodoro da Sicília e seria um oráculo délfico proferido (também) a Licurgo:

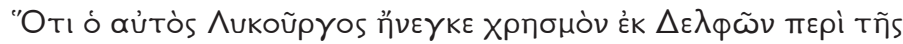

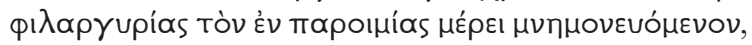

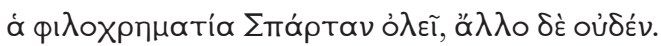

A lembrança de que o próprio Licurgo trouxe de Delfos um oráculo a respeito da avidez por dinheiro está no trecho do adágio:

A ganância arruinará Esparta, e nada mais.

A tendência entre os estudiosos é situar este provérbio no quinto século, seguindo proposta de Willamowitz ${ }^{23}$. Paul Cartledge ${ }^{24}$, por outro lado, acredita que sua origem é posterior à Guerra do Peloponeso. Van Wees ${ }^{25}$ voltou a propor uma ascendência arcaica para o provérbio. $\mathrm{O}$ autor verifica que o adágio é um verso hexamétrico perfeito ${ }^{26} \mathrm{em}$ dialeto dórico, e, como tal, dificilmente seria um produto da sabedoria popular, mas teria sido recolhido dos versos de algum poeta que compôs neste gênero. ${ }^{27}$

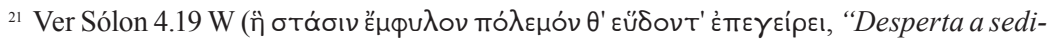
ção civil e a dormente guerra"). Xenófanes 1.20-23 W rejeita como comportamento ade-

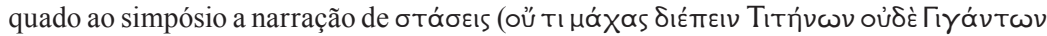

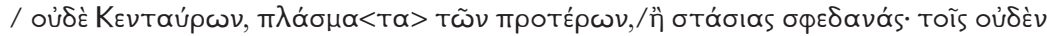
хрпото̀v Ěveotıv, "e não devem narrar combates de Titãs, de Gigantes,/de Centauros, ficções dos antigos,/ou ardentes sedições, nelas não há nada útil”)

${ }_{22}$ É o fragmento 3 da edição de T. Bergk, Poetae Lyric Graeci, Leipzig: 1882.

${ }_{23}$ 1900, p.108, n.1 apud Van Wees, 1999, p. 27, n.6

${ }^{24}$ Cartledge, P. Agesilaos and the crisis of Sparta, Duckworth, London, 1987, p.403

${ }^{25}$ H. Van Wees, 1999, p.2-3

${ }^{26}$ Embora ele fosse conhecido de outras maneiras. Ver Plutarco, Moralia, 239 f ( $\dot{\alpha}$ pı $\lambda$ o-

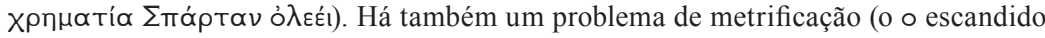
como breve antes de $\chi \rho$ em $\phi ı \lambda о х \rho \eta \mu \alpha т i ́ \alpha)$. West, contudo, encontra casos similares (1974, p.114).

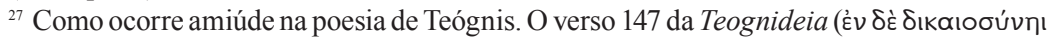


Quais seriam os candidatos? Para Van Wees, Terpandro seria o autor deste verso - poeta que teria usufruído de fama na Esparta do século VII a.C. e cujos poemas em hexâmetro seriam um misto de dórico e jônico.

Por conta do dialeto, notadamente dórico por causa do uso de $\alpha$ longo, Van Wees prontamente descarta que os versos possam ter vindo de um oráculo, como afirma Diodoro, ou que sejam provenientes da obra de um poeta elegíaco, uma vez que ambos são compostos em dialeto jônico. Há possibilidade de contrapor essa hipótese: um oráculo poderia ser retransmitido e alterado no processo de sua transmissão ${ }^{28}$. A poesia elegíaca, embora o emprego do jônico seja um elemento da composição genérica, também pode apresentar registros em outros dialetos, como demonstra a própria poesia de Tirteu, com alguns doricismos ocasionais ${ }^{29}$ e Sólon, que apresenta alguns resquícios do ático ${ }^{30}$. Alguns explicam tais resquícios como inépcia dos poetas ${ }^{31}$; Gentili ${ }^{32}$ chega a supor que os poemas de Tirteu foram compostos originalmente em dórico, e sua redação posterior em jônico, mantendo os doricismos apenas nos passos em que a métrica poderia ser comprometida. Noussia ${ }^{33}$ propõe que os aticismos encontrados nas elegias de Sólon poderiam ser um meio desenvolvido pelos poetas elegíacos a fim de estabelecer um diálogo entre o local e pan-helênico.

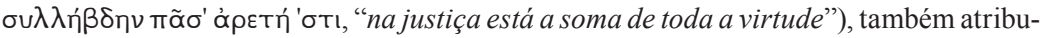
ído a Focílides (fr.10 W), é um provérbio no tempo de Aristóteles, e também os hexâmetros

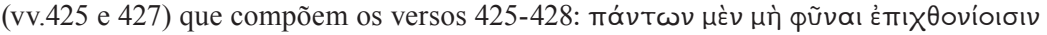

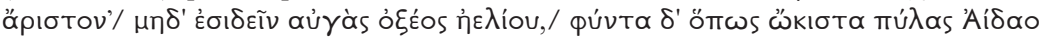

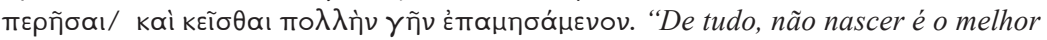
para os sobre a terra/ e não contemplar os raios do aguçado sol/Mas, nascido, cruzar o mais rápido os portais do Hades/ e jazer, enterrado por muita terra." O oposto também parece ser verdadeiro, e Teógnis entrelaça a seus pentâmetros versos que poderiam ser

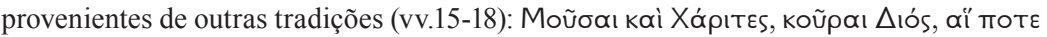

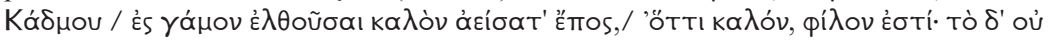

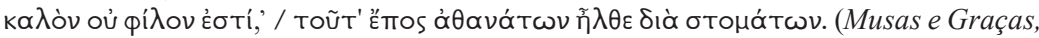
filhas de Zeus, indo outrora / às núpcias de Cadmo o verso cantaram:/ "o belo é amável, o não belo não é”/ este verso partiu de imortais lábios.)

${ }^{28}$ Ver L. MAurizio, Delphic Oracles as Oral Performances: Authenticity and Historical Evidence. ClAnt, 16.2, 323, 1997.

${ }^{29}$ Ver M.L.West, Studies in Greek Elegy and Iambus. Berlin/ New York, Walter de Gruyter, 1974, p.77.

${ }^{30}$ Os manuscritos do fr.4 W de Sólon apresentam Euvouía, o a longo alterado para $\eta$ na edição de West.

${ }^{31}$ A.W.H.Adkins, Poetic craft in the Early Greek Elegists. Chicago/London, University of Chicago Press, 1985, p.67

${ }^{32}$ B.Gentili, Poetry and Its Public in Ancient Greece: From Homer to the Fifth Century, London, The John Hopkins University Press, 1988, p.230

${ }^{33}$ M.Noussia, 2001, p. 349-50, apud E. Irwin, 2005, p.85,n.1) 
Nossa cidade jamais se perderá, por desígnios de Zeus e vontade dos ditosos Deuses imortais.

Uma guardiã tão magnânima, de um poderoso pai, Palas Atena, sua mão têm sobre ela.

Mas, eles próprios, os cidadãos, querem com tolices destruir a grande cidade, persuadidos por riquezas.

Dos líderes do povo injusta é a mente; a eles muitas dores está reservado sofrer por seu grande excesso.

Para Teógnis, a üßpıs (Hýbris, "desmesura" ou "excesso") é a única

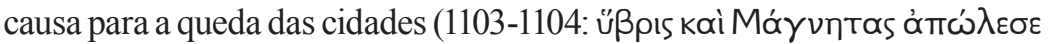

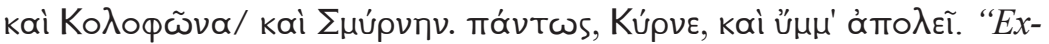
cesso perdeu Magnésia e Colofon, /e Esmirna: Decerto, Cirno, vos perderá também”). Esta ưßpıs, em outros passos da Teognideia, está associada às injustiças cometidas pelos líderes em vista de poder, proveito pessoal (v. 46:

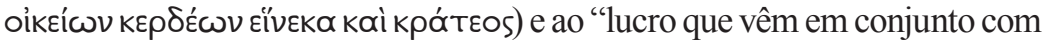

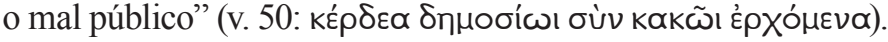

Esse tema constitui uma tradição comum à elegia grega arcaica, devido a seu tom frequentemente moralizante, pondo em causa uma an-

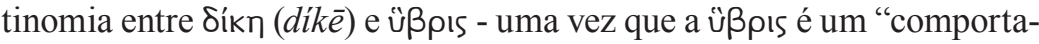
mento excessivo que transpõe os limites do que é correto e provoca voluntariamente a injustiça" ${ }^{37}$. Não é incomum, portanto, que üßpıs apareça como um sinônimo virtual de ớbıkía (adikía, injustiça), como ocorre em Hesíodo (O. vv.215-286). ${ }^{38}$

Que Tirteu tenha tratado da questão da Síkn em seu poema não nos parece surpreendente, dado o título pelo qual a sua obra ficou conhecida na posteridade. A Eunomia é um ideal oligárquico de justiça ${ }^{39}$, uma condição em que o estado é obediente às leis que já foram estabelecidas ${ }^{40}$.

Se este é o caso, como veremos, a única discrepância do argumento de Tirteu em comparação com o de outros poetas da tradição é sobre quem recai a responsabilidade destes excessos: enquanto Sólon e estes versos de Teógnis atribuem-no à falta de juízo das oligarquias, Tirteu deve ter mencionado em algum momento a фı das consequências da Guerra Messênia. ${ }^{41}$

\footnotetext{
${ }^{37}$ Ver Del Grande, 1947, p.1 apud G.Ragusa, Lira, Mito e Erotismo. Afrodite na Poesia Mélica Grega Arcaica, São Paulo: Editora da Unicamp, 2010, p.123.

${ }^{38}$ J.F.McGLEw, Tyranny and political culture in ancient Greece. Ithaca/ London:Cornell University Press 1993, p.59

${ }^{39}$ K.Raaflaub, 2006, p. 392

${ }^{40}$ A.Andrewes, Eunomia. CQ 32.2, 91, 1938.

${ }^{41} \mathrm{O}$ que também não deveria constituir nenhuma inovação: na própria Teognideia já
} 


\section{O Fragmento 2 W}

Antes de 1971, apenas quatro versos deste fragmento da Eunomia eram conhecidos, tendo sido conservados por Estrabão (Geografia, 8.4.10). $\mathrm{O}$ autor recorre aos versos de Tirteu com o fito de comprovar a nacionalidade espartana do poeta, verificando o uso da primeira pessoa do plural

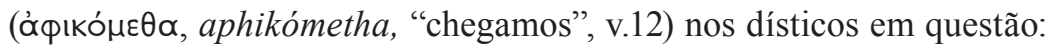

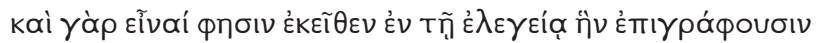
Eùvouíav.

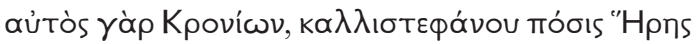

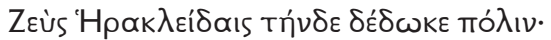

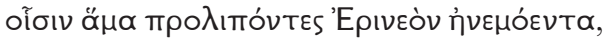

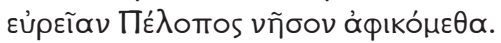

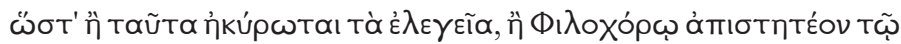

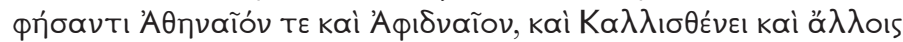

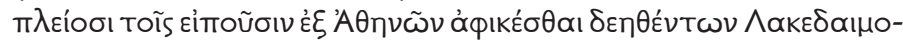

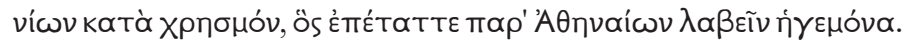

De fato, dizem que ele é dali (sc. da Lacedemônia), na elegia que intitularam como Eunomia:

Pois o Crônida em pessoa, esposo de Hera bem-coroada

Zeus, deu aos Heraclidas esta cidade:

junto deles, deixando Eríneo batida pelos ventos

à vasta ilha de Pélope chegamos

De maneira que, ou esta elegia é espúria, ou deve-se desacreditar Filocoro (328 F 215), que o declara Ateniense e de Afidna e também Calístenes (124 F 24) e a maioria restante, que dizem que ele veio de Atenas porque os Lacedemônios necessitavam, segundo o oráculo que lhes ordenou obter um comandante junto aos atenienses".

Analisando estes versos, Francke ${ }^{42}$ julgou que eles faziam parte de uma exortação, mais precisamente após o dístico inicial do fragmento

se pode notar que uma multiplicidade de opiniões permeava o tema (vv.53-54, 57-58:

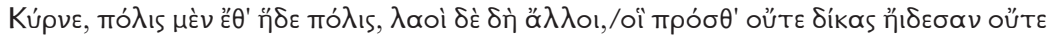

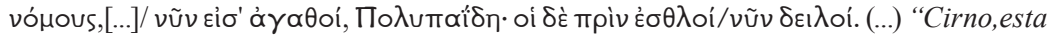
cidade é ainda uma cidade, mas outro é o povo./Os que antes não conheciam nem as leis , nem os costumes[...]/agora são os bons, Polipaides, enquanto os que antes eram nobres/ agora são desprezíveis". Tradução de Viviane M. Ishizuka, 2002). A aparente contradição na Teognideia pode ser entendida, como quer Faraone (2008, p.79), como produto da catena simposiale que fazia parte do ambiente dos poemas elegíacos.

${ }_{42}$ 1816, p.134 apud Bach 1831 p.82 
$11 \mathrm{~W}$ ("Mas porque sois da estirpe do invicto Héracles, / coragem, Zeus ainda não virou o rosto"), hipótese já rejeitada por Bach (1831, p.83) e por todos os editores subsequentes, em favor da unidade dos versos citados por Estrabão ${ }^{43}$. Prato ${ }^{44}$, seguindo a opinião comum, considerava que este poema muito provavelmente dava início à Eunomia.

A publicação do Papiro Oxirrinco 2824, de fins do século I ou início do século II d.C tornou estas suposições irrelevantes ao acrescentar novos versos à passagem recolhida por Estrabão:

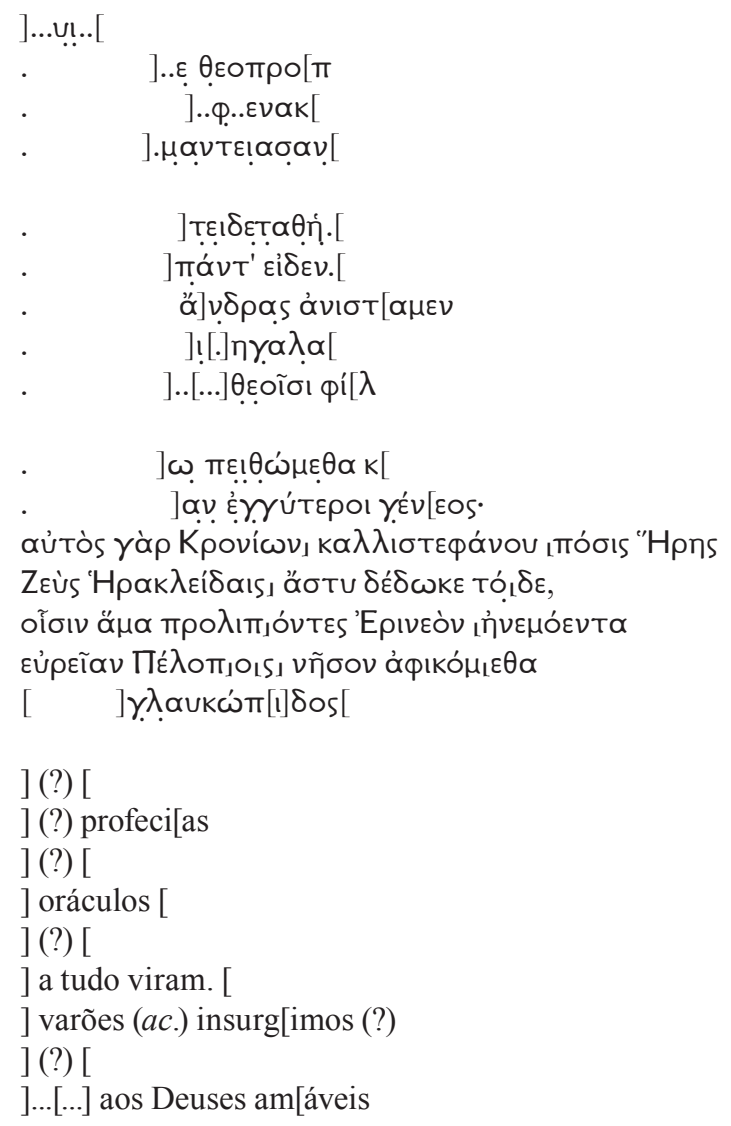

\footnotetext{
${ }^{43}$ Visto que no século XIX considerava-se que a Eunomia consistia de uma coletânea de elegias cívicas, e não um longo poema narrativo, como se argumenta hoje (Ver C. PRATo, Tirteo. Introduzione, texto critico, testimonianze e commento. Roma: Edizioni dell' Ateneo. 1968. 1968, p.09)

${ }^{44}$ C.Prato, 1968, p.61
} 


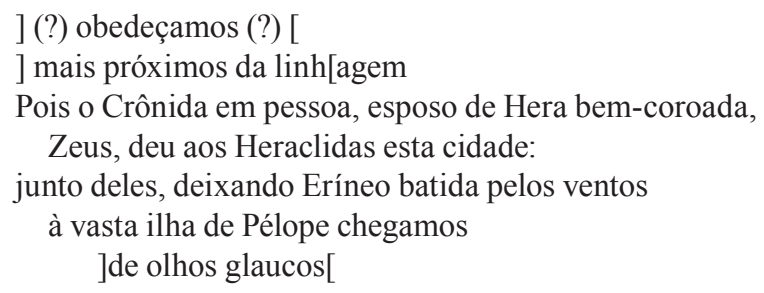

Embora muito lacunares, os novos versos possibilitaram a formulação de hipóteses mais consistentes sobre o poema. A primeira palavra inteligível é $\theta \varepsilon о \pi т р о т і ́$ s ( theopropías, "profecias", fr.2.2 W); Em seguida

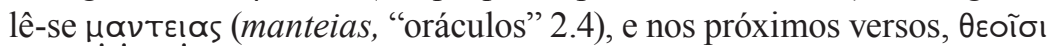

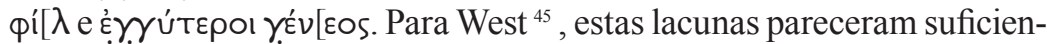
tes para afirmar que o poeta alude aqui a oráculos e aos reis de Esparta - eles próprios "amados por Deuses" e também os mais próximos da raça dos imortais.

Além disso, a menção a oráculos e profecias talvez ligasse esse fragmento ao $4 \mathrm{~W}$, sugerindo que ambos pudessem fazer parte de um mesmo poema, como já se supunha anteriormente devido à temática cívica comum a ambas as elegias, em oposição às outras de conteúdo bélico ${ }^{46}$. O que restou do verso 10 foi um subjuntivo exortativo na primeira pessoa do

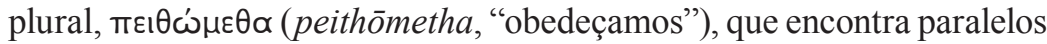
em outras elegias marciais (10.13-14 W, e 19.11-12, onde se utiliza o futuro indicativo) e pode indicar tanto um discurso feito por uma personagem como a voz do próprio Eu elegíaco.

A interpretação proposta por West ${ }^{47}$ para estes versos é a mais aceita: no poema, Tirteu exortaria seus interlocutores a obedecerem aos reis (vv.10), cuja autoridade deve-se à estima dos Deuses (vv.9) e ao seu parentesco divino (vv.11). Uma prova dessa ancestralidade é que a própria região do Peloponeso, para onde os reis conduziram o povo (vv.14-15), é um presente de próprio Zeus (vv.12-13). ${ }^{48}$

Pela sequência dos versos 2-7, não seria estranho supor que o poeta estivesse na verdade exortando guerreiros a uma ação bélica anunciada

\footnotetext{
${ }^{45}$ M.L. West, 1974, p.184

${ }^{46}$ C.Prato, 1968 , p.61

${ }^{47}$ M.L. WeSt, 1974, p.184

${ }^{48}$ West, 1974, p. 184: “Os versos [do fr.4 W] poderiam situar-se logo após o fr.2 W, onde a referência aos oráculos é seguida depois de alguns versos pela exortação: "Obedeçamos [aos reis; pois eles] estão próximos [dos Deuses], uma vez que Zeus em pessoa concedeu esta cidade aos filhos de Héracles".
} 
por um oráculo ou então mencionando brevemente alguma batalha antiga dos Heraclidas. O verso 7 ( $\propto] \nu \delta \rho \alpha \varsigma$ ávııoт $[\alpha \mu \varepsilon v$ ) , embora muito danificado, guarda semelhanças com passagens de elegias exortativas de Tirteu,

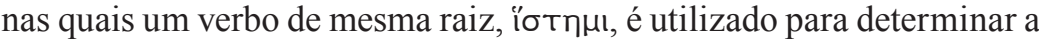
postura ideal de um varão na guerra, diante de seu inimigo. Quase sempre a ideia é complementada por verbos que indicam movimento $(11.29 \mathrm{~W}$,

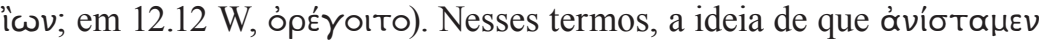
pudesse ter aqui algum sentido de erguer-se para lutar - já atestado em outros textos $^{49}$ - torna-se mais atraente e pode ser reforçada pelo uso de őv $\delta \rho a, s$, termo que significa na poesia de Tirteu exclusivamente o homem envolvido em ação militar, i.é, o guerreiro. ${ }^{50}$

Os versos citados por Estrabão (vv.12-15) deviam tratar de um episódio da pré-história de Esparta, o chamado "Retorno dos Heraclidas". A história começa com a luta entre Héracles e os filhos de Hipocoonte, que usurparam o trono de Esparta. Vitorioso, o primeiro retorna a cidade ao seu legítimo rei, Tíndaro. Com a morte deste o trono deveria passar aos descendentes de Héracles, mas em vez disso quem o herda é Menelau, e em seguida Orestes, que reinaria sobre as duas coroas Atridas. Os Heraclidas retornariam em conjunto com os Dórios, povo que habitava a Grécia Central, para reclamar seu direito real apenas durante o reinado de Tisâmeno, filho de Orestes ${ }^{51}$

A relação com o mito é comprovada pela menção à "Eríneo batida por ventos" no verso 14. Trata-se de uma das quatro cidades da tetrápole dórica, na Grécia Central, e não uma comunidade ática próxima a Elêusis, como postularam alguns estudiosos que defendiam a procedência ática de Tirteu (Como, por exemplo, Thiersch ${ }^{52}$ ) Estrabão (9.4.10) é quem dá a localização exata da cidade e informa sobre o mito do Retorno:

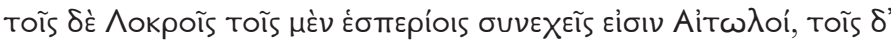

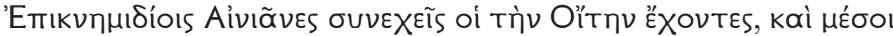

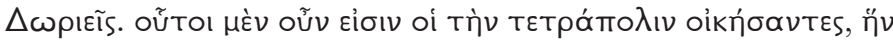

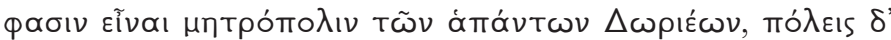

\footnotetext{
${ }^{49}$ LSJ "stand up [to fight against]: Il.23.635; Od.18.334.

${ }^{50}$ Por exemplo, 10. $18 \mathrm{~W}$, onde este sentido parece bem marcado: "não tende amor à vida,

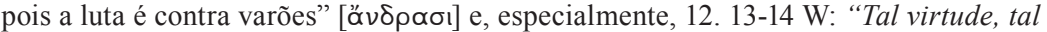

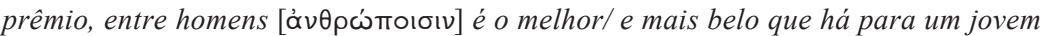

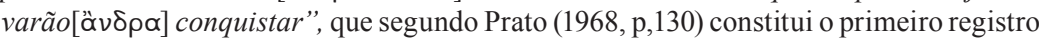
em nossa literatura supérstite de uma distinção claramente marcada entre àv $\theta \rho \omega \pi$ os (ánthropos), "humano" e ơvíp, (anér) "varão".

${ }^{51}$ Ver M.NAFISSI, 2009, p.118

${ }^{52}$ 1826, p. 593 apud Bach, 1831, p.80
} 


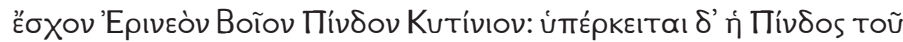

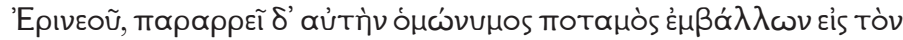

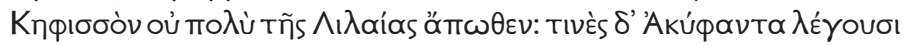

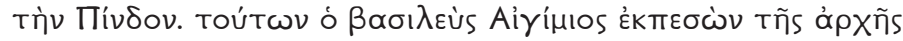

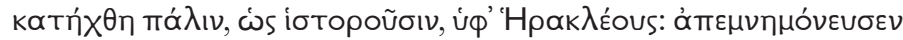

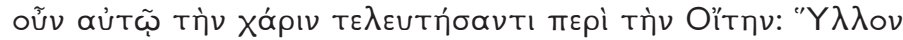

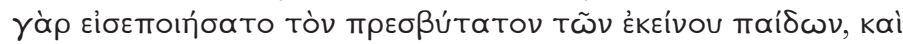

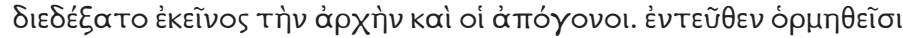

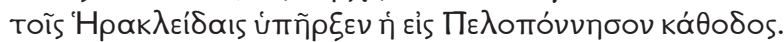

Contíguos aos Lócrios ocidentais estão os Etólios, enquanto os Enianos, que habitam o Eta, [são] contíguos aos [Lócrios] Epicnemídios; no meio [estão] os Dórios. Esses Dórios são os que habitam a Tetrápole, a qual afirmam ser a capital de todos os Dórios. Suas cidades eram Eríneo, Beos, Pindo e Citínio. Pindo estava localizada acima de Eríneo, e ao seu lado corre o rio homônimo, que deságua no Cefiso, não muito longe de Lileia. Alguns chamam o rio Pindo de Acifante. O rei destes [Dórios], Egímio, foi derrubado e depois reconduzido novamente ao poder, como informam, por Héracles. [Egímio] relembrou o favor quando da morte de Héracles no Eta: pois adotou Hilo, o mais velho dos filhos de Héracles, e ele e seus descendentes o sucederam no poder. A partir daí, teve início o retorno dos Heraclidas, que partiram para o Peloponeso.

Prato ${ }^{53}$ parece estar certo quando diz que o verso 12 marcaria o início de uma nova composição, uma transição para algo novo que será narrado. Marca este novo início a ênfase na figura de Zeus: o verso inicia-se com um molosso (aủtòs yà p), um dos recursos preferidos de Tirteu ${ }^{54}$ que imprime não apenas solenidade como também, nesse caso, chama a atenção dos ouvintes para o novo tema que virá.

Após a cesura, Zeus é qualificado por sua associação com Hera pelo do uso do epíteto tradicional móors "Hpns (pósis Hérēs, "esposo de Hera"). Na Ilíada e na Odisseia este epíteto aparece, por questões métricas, acom-

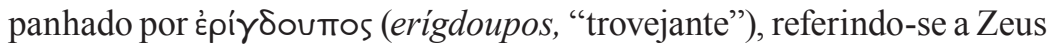
(Il. 10.329, 13.154, 16.88; Od.8,465, 15.112, 15.180) e raramente por um

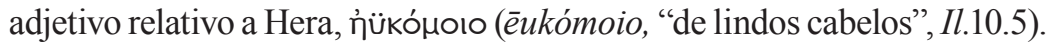
Tirteu opta por realçar a representação da Deusa referindo-se a ela com um epíteto mais incomum e vívido, ausente na Ilíada e na Odisseia, mas presente na tradição épica para designar Afrodite (na célebre inscrição da Taça de Nestor) e Deméter (H.Cer. v.251).

${ }^{54}$ A.W.H.Adkins, Callinus 1 and Tyrtaeus 10 as poetry. CPh 81, 185, 1977. 
Contudo, mesmo que na tradição épica ser referido como "Esposo de Hera" seja um motivo de honra para Zeus, poderia soar estranho à primeira vista que o poeta tenha enfatizado e escolhido justamente a este epíteto para designar Zeus em um poema que menciona os descendentes de Héracles, como já notou antes a maioria dos comentadores, como Defradas (1962, p.16), Prato (1968, p.61), Vox e De Martino (1996, p. 548).

Todos também informam sobre a amplitude do culto à Hera na Lacônia; Desde a antiguidade, Esparta estava entre as três cidades mais ca-

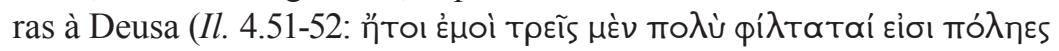

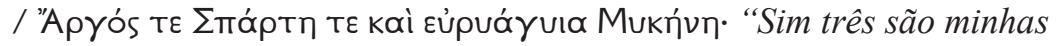
cidades, as mais queridas:/ Argos e Esparta e Micenas de amplas vias"). Na própria poesia de Tirteu, Hera é denominada aíooíns (aidoíēs, "respeitável”, 23. $17 \mathrm{~W}$ ); Pausânias já informa sobre várias localidades dedicadas a Hera na antiga Lacônia (3.18 ss.) e que o próprio Héracles teria fundado um templo a ela, em virtude de sua não intervenção durante a luta contra os Hipocoontidas (3.15.9):

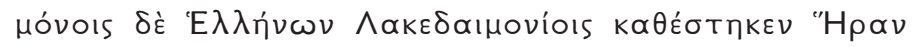

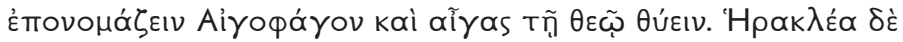

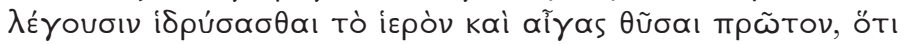

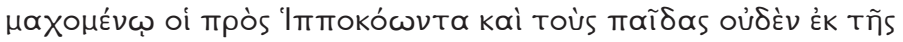

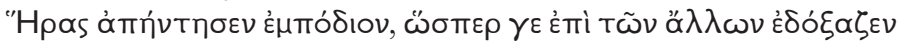

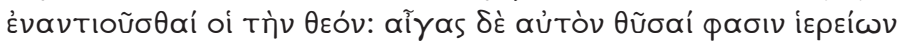

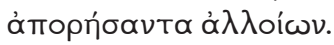

Dos Helenos, apenas entre os Lacedemônios atribui-se à Hera o epônimo "Come-cabra" e sacrificam cabras à Deusa. Conta-se que Heracles fundou um templo e foi o primeiro a sacrificar cabras, porque, enquanto lutava contra Hipocoonte e seus filhos, não encontrou nenhum obstáculo de Hera, mesmo que em outras ocasiões pensasse que a Deusa se lhe opunha. Diz-se que ele sacrificou cabras, por carecer de outras opções de sacrifício.

Se no verso anterior era Hera quem recebia o maior destaque do po-

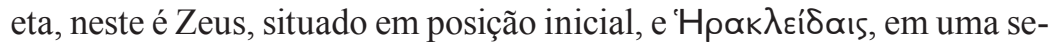
quência de longas que ocupa todo o primeiro hemistíquio do pentâmetro, em procedimento similar ao do verso anterior. Nesse sentido, é curioso notar que o poeta parece interessado em assinalar, iniciando cada verso com espondeus, uma marcha descendente que parte do meio divino para a realidade dos mortais; no verso 12, figura "o Crônida em pessoa" aủ tòs yà

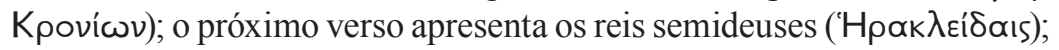


por fim, os mortais são prenunciados no verso 14 pela anástrofe (oĩoıv

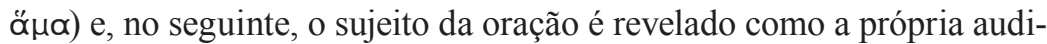
ência do poema, personificada na realidade da performance (đ’́ı

Este recurso que confunde um passado mítico distante a uma realidade atual da performance é também verificável em outros registros e constitui-se como um elemento tradicional de toda a literatura grega arcaica e clássica ${ }^{55}$ No caso da elegia de Tirteu, o poeta preocupa-se em forjar uma conexão entre passado, presente e futuro, e definir "um grupo coeso de todos os espartanos, vivos ou mortos" ${ }^{956}$.

Em um passo surpreendentemente similar ao poema de Tirteu - que poderia apontar para uma tópica comum ao período - Mimnermo também correlaciona a si mesmo e sua audiência aos colonizadores de Cólofon, provenientes de Pilos $^{57}$ :

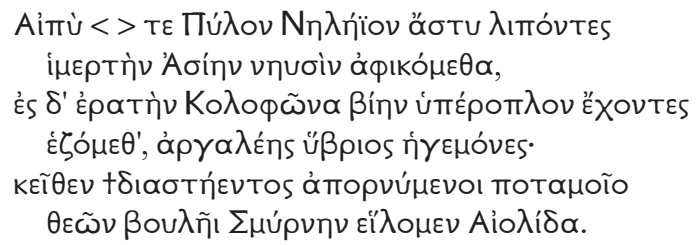

(?)...deixando Pilos, a cidade de Neleu, à Ásia adorável em navios chegamos e na amável Cólofon com soberba força nos assentamos, condutores da dura violência: daí, atacando desde o rio [?] por querer dos Deuses conquistamos Esmirna Eólia.

\footnotetext{
${ }^{55}$ São exemplos na elegia grega arcaica Calino 2, 2a, o novo fragmento de Arquíloco ("Télefo"), Mimnermo 11-14 W, Simônides 11 W.

${ }^{56}$ E.STehLe, 1997, p. 52

${ }^{57}$ Embora a temática do poema pareça mais adequada à Esmirneida, a fonte (Str. 14.1.4: "Por fim, expulsos pelos Eólios, fugiram para Cólofon. Depois disso, atacaram daquela região e reconquistaram a sua terra. Exatamente como Mimnermo declara em Nannó, depois de mencionar que Esmirna sempre foi objeto de conflito") atribui os versos à Nannó, poemas menores, que, por consequência, eram apresentados no ambiente do simpósio. Seria um erro cometido por Estrabão, ou a passagem, originária da Esmirneida, teria sido reformulada para uma performance simpótica? (E.L.BowIE, 'Wandering Poets, Archaic Style' in: I.RUTHERFORD; R.HunTER (eds.) Wandering Poets in Ancient Greek Culture: Travel, Locality and Pan-Hellenism. Cambridge/New York, Cambridge University Press, 2009,p.113 n.11). A segunda opção é interessante, caso se considere que o poeta trabalha aqui com termos do universo erótico para definir Cólofon e Esmirna. O mesmo uso é verificado em Tirteu $4.4 \mathrm{~W}$.
} 
Bowie ${ }^{58}$ considerou que o $\pi \varepsilon \mid \theta \omega ́ \mu \varepsilon \theta \alpha$ do verso 10 vem do discurso de um personagem, e admitiu a possibilidade de o áqıкó $\mu € \propto \alpha$ do verso 15 também ser parte deste mesmo discurso, mas, visto que o próprio Estrabão provavelmente não lia o poema dessa maneira, Bowie ${ }^{59}$ reformula a sua hipótese e afirma que a Eunomia poderia ter sido um poema predominantemente exortativo com breves passagens narrativas, de modo "funcionalmente similar aos elementos narrativos nos discursos de personagens na Ilíada". Se Cristopher Faraone ${ }^{60}$ está certo em suas hipóteses sobre a estrutura da poesia elegíaca grega arcaica, poderíamos estar de fato diante de um poema exortativo com partes narrativas, em que passagens exortativas (como provavelmente seriam os vv.2-11) alternam-se com trechos narrativos (vv. $12 \mathrm{ss}$.)

Note-se que sugestão parecida à de Bowie já está no Studies in Elegy and Iambus de Martin West que alude a uma possível identidade entre a Eunomia e outros poemas comprovadamente exortativos, como a $\mathrm{Sa}$ lamina de Sólon (fr.1-3 W) - uma identidade que não é só de tema, mas também de ocasião de performance. ${ }^{61}$

\section{Estratégias comunicativas no fr. 2 W}

Poderíamos, assim, entender o simpósio como um ambiente adequado para a apresentação deste canto? Uma vez que não é possível precisar a extensão exata da Eunomia, é profícuo verificar se as estratégias comunicativas presentes no poema podem fornecer algum indício das circunstâncias em que o fragmento $2 \mathrm{~W}$ poderia ter sido apresentado.

D' Alessio ${ }^{62}$ assinala que esta estratégia consiste no emprego da primeira pessoa do plural: ao empregá-la, o poeta torna possível que qualquer indivíduo da comunidade espartana possa se identificar na voz poética. Tirteu estaria, assim, na contramão de outros poetas gregos arcaicos que tinham o simpósio como horizonte, visto que estes se ocupavam de, muitas vezes, enfatizar o seu próprio Eu poético ${ }^{63}$ e retratar uma visão de mundo

\footnotetext{
${ }^{58}$ E.L.Bowie, 1986, p.31

${ }^{59}$ E.L.BowIE, 2001, p.47

${ }^{60}$ C. A.Faraone, The Stanzaic Archicteture of Early Greek Elegy, Oxford, University Press, 2008, p.156

${ }_{61}$ "Se foi assim, [a elegia narrativa] é semelhante à elegia marcial ou político-exortativa e pode ser imaginada cantada em circunstâncias semelhantes” (1974, p.14).

${ }^{62}$ G.B. D’Alessio, 2009, p.151-156

${ }^{63}$ Arquíloco, fr. $1 \mathrm{~W}$ ( "sou servo do senhor Eniálio e/ das musas o amável dom conheço", Tradução de Paula da Cunha Corrêa, 2009) Teógnis (vv. 19-23, "Cirno, que o selo de
} 
que era compartilhada apenas pelo grupo que participava do simpósio. ${ }^{64}$ Portanto, segundo o autor, não haveria a necessidade que alguém incorporasse a voz de "Tirteu" em suas performances ${ }^{65}$, pois o próprio poeta já personifica a comunidade espartana em suas elegias; $\mathrm{O}$ autor justifica que o uso de 'Hpak $\lambda \varepsilon i ́ \delta \propto ı s$ (vv.13) remete a esta coletividade, que diz respeito a todos os espartanos, e não apenas a um grupo que clama ancestralidade divina. Assim, a poesia de Tirteu está em oposição à poesia simpótica aristocrática, pois não apresenta a linguagem sectária das heterias, mas antes coloca em cena todo o povo de Esparta. As divisões que a elegia tirtaica engendra são apenas de funções militares que devem ser desempenhadas por cada grupo. Desse modo, D’Alessio conclui que os poemas de Tirteu encontrariam seu espaço ideal no peculiar banquete comum espartano, a syssitia.

Há espaço para discordâncias da hipótese de D'Alessio: uma delas é que a maioria dos estudiosos estabelece que o início desta instituição espartana se deu em meados do século VI a.C., anos depois do período de atividade poética de Tirteu, e que antes disso, os simpósios em Esparta não apresentavam grandes diferenças com os de outras poleis gregas ${ }^{66}$. Ainda que se possa considerar a syssitia como espaço de reperformance privilegiado para a poesia de Tirteu (como de fato deve ter sido), não se pode afirmar com exatidão que o poema difundia um ideal de comunidade, uma vez que mesmo no interior da comunidade de homoioi que integrava a syssitia havia distinções que se baseavam em ideais aristocráticos como riqueza, nascimento, mérito e idade ${ }^{67}$. É correta a sugestão de que a única divisão encontrada em Tirteu é de grupos militares, mas esta divisão na verdade promove um componente aristocrático: apenas os mais abastados podiam pagar pela panóplia, restando a outros o uso de armas mais rudimentares ${ }^{68}$.

minha habilidade poética seja colocado sobrel estes versos, e o roubo deles sempre será notado./Ninguém trocará o pior pelo bom, que está à mão/ Assim, todo homem dirá: "São os versos de Teógnis/de Megara", célebre entre todos os homens". tradução de Viviane M. Ishizuka,2002), Sólon (fr.1W: "Eu mesmo, um arauto, vim da adorável Salamina/ e um adorno da palavra, o canto, anteponho à fala")

${ }^{64} \mathrm{Um}$ exemplo pode ser o fragmento $69 \mathrm{~V}$ de Alceu.

${ }^{65}$ Com em alguns poemas de Safo (1.19-20 “Quem, ó Safo, te maltrata?”- trad. Giuliana Ragusa, 2005, grifos meus), Hipônax (34: Pluto, Deus da riqueza (porque é cego demais)/ nunca me veio em casa e disse: "Hipônax,/dou-te trinta minas de prata/ e muitas outras coisas." - pois é um desgraçado no coração") e Alceu (fr. 129 e $130 \mathrm{~V}$ )

${ }^{66}$ E.IRwin, 2005, p.32 n.40

${ }^{67}$ Hodkinson,S. 'Social Order and Conflict of Values in the Classical Sparta' in WHITBY, M. Sparta. Edinburgh: Edinburgh University Press. 2002, p.108

${ }^{68}$ IRWIN, 2005, pp.291-296 
Nesse sentido, de maneira similar a Andrew D. Morrison ${ }^{69}$, que analisou os narradores na poesia grega arcaica, pode-se chegar à conclusão de que o uso de uma voz poética bem delimitada, e, por assim dizer, autorreferencial (como ocorre em elegistas como Sólon ou Teógnis) ou o uso de uma Eu coletivo como aqueles dos poemas de Tirteu é uma questão de estilo ou preferência particular de cada poeta - e não necessariamente de diferentes circunstâncias de performance. É comum, também, como observa Rösler ${ }^{70}$, que uma rememoração no espaço do simpósio esteja relacionada à comunidade, tornando nebulosos os limites do "eu" e do "nós" - uma vez que esta é uma festividade que define identidades de um grupo que se reúne por afinidades comuns. E como é comum no restante da poesia de Tirteu, tais afinidades se manifestam a partir da subordinação do povo às figuras aristocráticas - aqui representadas por Heraclidas - que assumem o papel de mantenedores da polis. Os versos 15 e 16 sugerem esta leitura: neles, o poeta deixa implícito que o povo (ao qual ele se inclui, talvez por intenções retóricas) obteve a cidade graças aos Heraclidas, que para lá o conduziu.

Title. Tyrtaeus $2 \mathrm{~W}$ and the poetics of Eunomia

AвSTRACT. It was claimed for a long time that Tyrtaeus' Eunomia (Fr. 1-4 W) was a narrative poem for the community and performed only in the space of public festivals. But the discussion remains open, especially because of the scarcity of fragments that survived. Instead of trying to argue about a specific circumstance of performance for that poem, this text aims to answer the following questions by offering a reading of Fragment $2 \mathrm{~W}$ : are there marks that distinguish a poetic confined to the public festival and other fitted to the sympotic environment? Are there points of contact between them? If so, it can be said that Tyrtaeus' Eunomia has such marks?

KEYWORDS. Tyrtaeus; Greek archaic poetry; performance; narrative elegy.

\footnotetext{
${ }^{69}$ A.D.Morrison, The narrator in Archaic greek and Hellenistic poetry. Cambridge, University Press, 2007, p.57

${ }^{70}$ W.RÖSLER, 1990, p. 233-234.
} 